\title{
USING GRAPHENE OXIDE-SILICA [GO-Si] NANO COMPOSITE ADSORBENT, REMOVAL OF HEAVY METAL IONS (LEAD AND MERCURY) FROM INDUSTRIAL WASTEWATER AND ANALYSING ITS PERFORMANCE
}

\author{
Jayakaran Pachiyappan* and Nirmala Gnanasundaram \\ School of Chemical Engineering, VIT University, Vellore-632014, Tamilnadu, India. \\ *E-mail: indujayakaran@gmail.com
}

\begin{abstract}
Nanoscale composite materials have an immense potential to cleanse wastewaters from multiple points of view, because of their higher surface potential and synthetic reactivity, peculiar mechanical quality, and cost-adequacy. This article focuses on the removal of highly harmful heavy metal ions, such as lead and mercury, using the efficient Nanocomposite adsorbent Graphene Oxide Silica [GO-Si], which was synthesized in this work. The effect of the initial $\mathrm{pH}$ of wastewater, its temperature, the dosage of adsorbent on the removal of lead as well as mercury was studied. Besides, the adsorption kinetics and mechanism on GO-Si composite were investigated. The greatest adsorption measure of lead and mercury on GO-Si achieved were 347.2 and $266 \mathrm{mg} / \mathrm{g}$, respectively. The morphology studies of GO-Si showed the presence of a highly porous surface which makes GO-Si most effective in terms of adsorption. The TEM, SEM studies confirmed the presence of Silica on the surface of the composite. Regeneration of composite adsorbent makes it worthy for five more cycles. Thus, the outcome of this study depicts that the GO-Si can be employed to remove environmental pollutants such as lead and mercury at low cost.
\end{abstract}

Keywords: GO-Si, Industrial Wastewater, Nanocomposite, Lead, Mercury, Adsorption.

(C) RASĀYAN. All rights reserved

\section{INTRODUCTION}

In recent decades, the production and discharge of huge amounts of hazardous and toxic effluent from different manufacturing units are increasing globally in an alarming manner. Among the different pollutants present in wastewaters, the presence of a wide range of chemicals, dyes, heavy metal ions, byproducts, residues, etc., in the effluent makes them more poisonous to life forms and direct release of the effluent without legitimate treatment could affect the biological system deadly. ${ }^{1}$

A considerable number of research studies have been directed to examine the effect and poisonous quality of pollutants on the biological system. Most of the pollutants contaminating water are creating serious health issues which persist affect the entire biodiversity. Considering various pollutants contaminating the water, the presence of heavy metal ion particles is found to be hazardous causing various health issues in living organisms. To overcome that, in this work removal of lead and mercury had been taken into account since due to the abundant discharge by various industries in the water bodies., 3

Now saying about Lead, it is the most generally used color additive substance for hair dyes. Even though it is not strongly perilous, but it has different hurtful effects, for example, difficulty in respiration particularly during inward breath or consuming sensations, queasiness, diarrhea as well as vomit, if it is consumed through mouth. ${ }^{4}$ Likewise, mercury present in wastewater causes abnormal health issues among the living organisms when consistently exposed. Various conventional wastewater treatment methods have been utilized to expel lead and mercury from wastewater such as physical methods that include adsorption, layer process as well as irradiation and layer process, chemical processes include oxidation procedure, ozonization, ion exchange, electro-coagulation and coagulation combined with flocculation and organic treatment which includes aerobic and anaerobic processes. Among these methodologies mentioned here, adsorption based methodologies integrated with actuated carbon, zeolite,

Rasayan J. Chem., 13(3), 2027-2035(2020)

http://dx.doi.org/10.31788/ RJC.2020.1335827 
RASĀYAN J. Chem.

Vol. 13 | No. 3 |2027-2035| July - September | 2020

silica composites are found to be effective. Thus, we must employ an eco-friendly as well as highly efficient adsorbent that has rapid adsorption of pollutants from wastewater at low cost. In associating with them, many research gatherings have examined the use of magnetic nanoparticles as adsorbent. ${ }^{5,6}$

Nanoparticles are highly invisible particles through naked eyes, with the size ranges 1 to $100 \mathrm{~nm}^{7}$. In comparison with conventional materials employed for several decades by the research community, nanosized adsorbents show much higher adsorption efficiency and quicker expulsion rate of hazardous and toxic adsorbed materials, from the wastewaters. ${ }^{89}$ It is worthy to say that, when the composite particle size is reduced to Nanoscale, considerable changes were observed in terms of physical, mechanical as well as optical characteristics of the adsorbents. In addition to these advantages, these nanomaterials have a higher surface area potential, which can prompt higher adsorption for pollutant expulsion. Along with this, the adjustment in the structure of pores also to be considered as an important criterion that relates to the quicker transportation of the pollutants to the interior sites of adsorbents, which will facilitate the adsorption in better manner. ${ }^{10}$

An interesting and current nano-material, which is a wellspring of extraordinary expectations among researchers across the world, is graphene and its oxide. Graphene, a two-dimensional carbon-based crystalline material, which usually possesses atomic thickness and developed as well as employed widely in recent years as one of the best highly useful chemical nanomaterials. Attributable to its remarkable mix of best of its kind properties, that enables it to be used in a large range of applications. GO is an oxidized chemical form of graphene. It consists of many molecular collections, for example, hydroxyl, carboxyl, and epoxy gatherings. In this manner, it is hydrophilic and acts as a soluble substance in water. It additionally has a highly negative charge thickness, due to the presence of oxygen-containing useful gatherings. ${ }^{1,11} \mathrm{GO}$ can be employed as metal cation exchange resin, on account of the ionic carboxyl groups, which permit the particle exchange with several metal cations or decidedly charged organic atoms. ${ }^{12}$ The carboxyl groups present in it can cooperate with several positively charged chemical species, such as metal particles, polymers, and biomolecules. ${ }^{12}$ Despite a wide range of industrial applications as well as advantages, this adsorbent has some demerits which include high capital expenses as well as the use of highly complex synthesis. ${ }^{13}$ Along with that, the expulsion of suspending adsorbents in wastewater from a ceaseless flow framework remains a challenge for the research community across the world. It is noteworthy to say that, magnetic separations are very rapid, easily adaptable, can be effectively robotized, and can accomplish the separations that would be unimaginable or unrealistic to accomplish by other techniques. $^{14,15}$

By utilizing it in adsorbent, specific control and separation within the sight of other suspended solids can be conveyed out. ${ }^{16,17}$ As an outcome, it is conceivable to attractively isolate selected target species legitimately out of unrefined organic procedure just by binding them on attractive adsorbents before the use of an attractive field. ${ }^{18}$ As of today, relatively few works have been studied by researchers worldwide on the use of attractive GO especially as an adsorbent for the removal of color from wastewaters.

A significant element of graphene oxide is the hydrophilic properties coming about because of its synthetic structure. Aside from the adsorption properties, graphene oxide has numerous different highlights utilizing to get polymer composites with uncommon properties. Similar to many other carbonbased materials, naming few: activated carbon, carbon nanotubes GO, more and more investigations concentrate on using graphene as an adsorbent for taking away of various pollutants, for example, dyes (Methylene blue, Rhodamine B, etc.)., heavy metal ions $\left(\mathrm{Pb}^{2+}, \mathrm{Hg}^{2+}, \mathrm{Sb}^{3+}\right.$, etc.), fluoride, phosphate, naphthalene, bisphenol and phenol. ${ }^{19}$ Graphene-related materials have emerged as new low-cost adsorbent techniques and removal of chemical nanoparticles from wastewater.

The utilization of mesoporous silica for hydrophilic as well as the high surface area along with modified GO produced an orderly porous network arrangement. Graphene oxide Silica (GO-Si) hybrid composite particles were synthesized by using the chemical process of tetraethyl orthosilicate (TEOS) a colorless liquid in the existence of super-hydrophilic inter layer GO derived from a modified Hummers method. All the research analysis insist that GO and GO-Si should be considered as fast, remarkable and universal method for adsorption technologies related to the removal, water pollution control, and remediation.

Therefore, our study aimed to combine two novel adsorbents; GO-attractive Silica nanoparticle (GO-Si) that exhibits not only have high adsorption rate and phenomenal regenerative ability but also shows the 
RASĀYAN J. Chem.

Vol. 13 | No. 3 |2027-2035| July - September | 2020

excellent effects on the simple partition after the adsorption process. Hence, the effect of thus incorporated adsorbents was studied in this work for the expulsion of lead and mercury from wastewaters was then investigated.
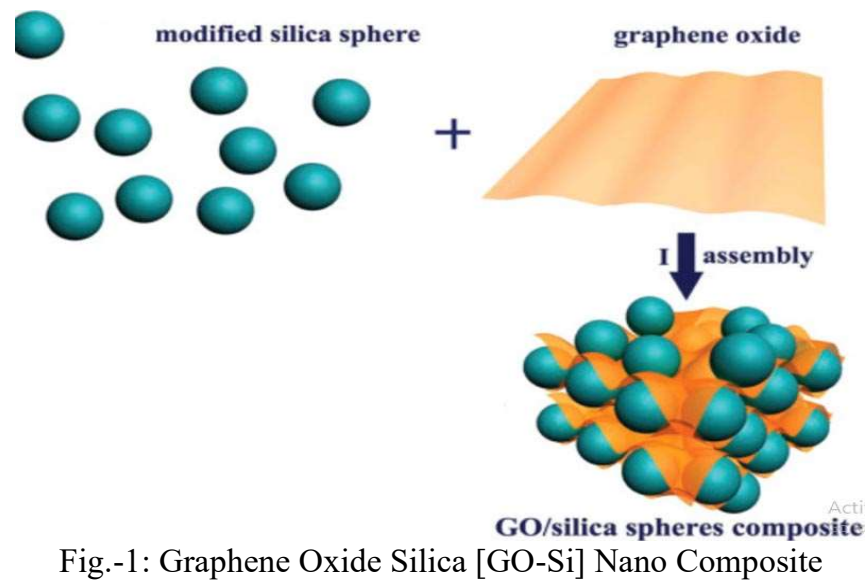

Fig.-1: Graphene Oxide Silica [GO-Si] Nano Composite

\section{Materials and Methods \\ GO-Si Adsorbent}

Elaborating GO-Si adsorbent, GO was synthesized by following basic methodology utilizing an adjusted Hummer's method. The detailed handling procedures involves 2 main steps as follows: (1) Pretreatment: $2.0 \mathrm{~g} \mathrm{GO}$ was scattered in $0.1 \mathrm{~L}$ of $80 \%$ ethyl alcohol by ultra-sonication, at that point they were filled into $0.3 \mathrm{~L}$ of $0.1 \mathrm{~mol} \mathrm{~L}^{-1} \mathrm{SiO}_{2}$. (2) Then, $0.025 \mathrm{~L}$ of $15 \mathrm{~mol} / \mathrm{L}$ ammonia was dropped into the above blend and was scattered by ultra-sonication. Finally, the mixture was dried and the dried product was stored in an air-tight container, till its further use.

Scanning electron microscopy (SEM) and transmission electron microscopy (TEM) images of nanocomposites were shown in Fig.-2 and Fig.-3, which clearly illustrate the presence of the silica nanoparticles grafted on the surface of GO, that results in GO-Si. Energy-dispersive X-ray spectroscopy (EDX) and X-ray diffraction (XRD) spectra illuminate the coexistence of silica and GO as composite Nanoparticles. The GO-Si showed the investigation of extremely improved thermal stability than that of GO according to thermogravimetric analysis (TGA).

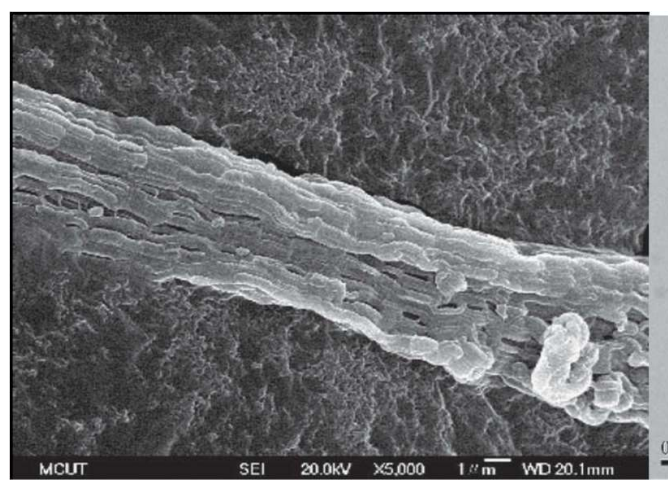

Fig.-2: SEM image of GO-Si Composite

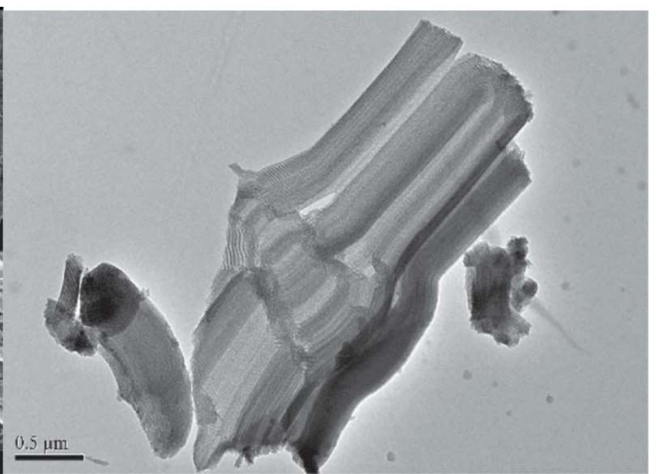

Fig.-3: TEM image of GO-Si Composite

\section{Lead}

Due to the rapid advancement in modern industry, various heavy metals ions are discharged in the water body, naming few: $\mathrm{Cd}(\mathrm{II}), \mathrm{Ni}, \mathrm{As}(\mathrm{III}), \mathrm{Co}(\mathrm{II}), \mathrm{Cu}(\mathrm{II}), \mathrm{Zn}(\mathrm{II}), \mathrm{As}(\mathrm{V})$, and much more, were discharged into the industrial wastewater, causing serious environmental pollution ${ }^{20}$. Lead or $\mathrm{Pb}$ (II) is the primary dangerous substantial metal, which is produced because of mining, electroplating, coloring, battery, textile, explosive, and different ventures. 
RASĀYAN J. Chem.

Vol. 13 | No. 3 |2027-2035| July - September | 2020

In recent decades, the medical community found that Lead is very harmful and it can cause serious damages in the kidney, liver, blood, nerve, and circulatory system of the human system. For the sake of the betterment of humans, it is highly important to adsorb $\mathrm{Pb}$ (II) from water in a basic, proficient, and ecologically friendly manner. Several attempts were made to explore the adsorption potential of metal expulsion from galvanizing wastewater. Among the numerous studies made, lead was found to have the most astounding focus $\left(\sim 2 \mathrm{mg} \mathrm{Pb} / \mathrm{dm}^{3}\right)$ in the wastewater sample. The quantitative analysis of the wastewater was inspected by UV spectrophotometry. The investigations demonstrated that graphene oxide combined with silica influences the physical properties to adsorb much more metal ions.

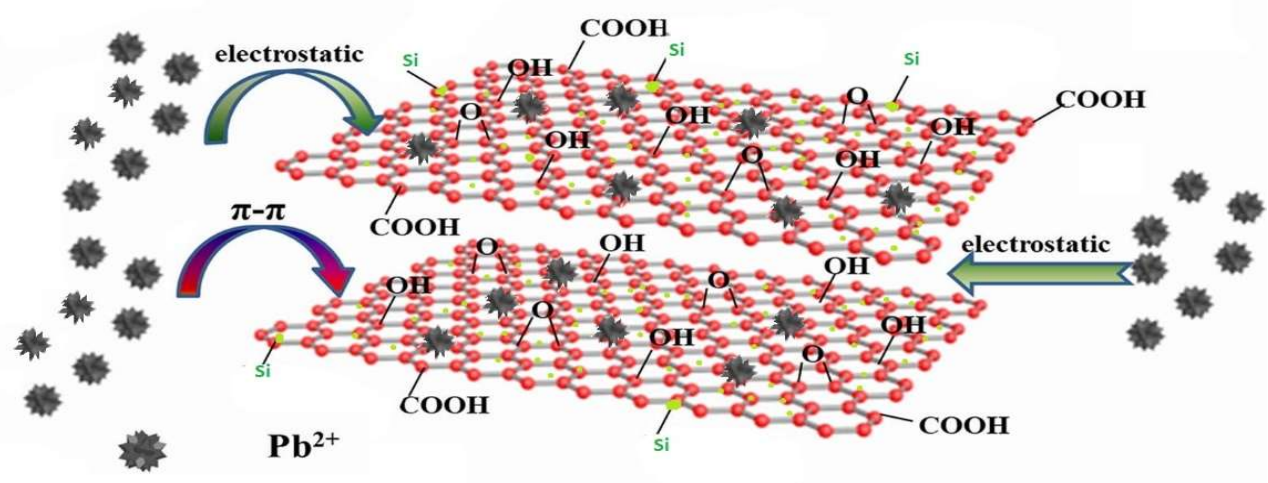

Fig.-4: Adsorption of Lead by GO-Si Composite

\section{Mercury}

Heavy metal ions, such as lead, zinc, mercury, arsenic, and much more are indiscriminately released into the water bodies. Among these heavy metal ions polluting the water bodies, mercury is one among the hazardous micropollutant which causes a variety of diseases by affecting neurological and renal activities. It is usually discharged from several industrial activities, for example, coil ignition, gold mining, battery industry, etc. Generally, mercury metal ions are brought into the water as $\mathrm{Hg}$ (II) particles. In this aspect, it is important to abuse viable approaches to expel $\mathrm{Hg}$ (II) particles from tainted water.

The GO-Si Nanocomposite solid-phase adsorbents are used to adsorb mercury particles from water contaminations. Mercury can be adsorbed into human bodies through skin, lungs, and gastrointestinal tract bringing about a few intense and perpetual issues, for example, emphysema, hypertension, sensory system harm, cancer, and testicular decay. As a substantial metal, mercury surged into aquatic environments from industrial procedures, including metal handling, leather tanning, metal cleaning, electroplating, paint producing, metal plating, mining, pottery, battery fabricating, oil refining, plating, electrical, manures, waste disposal, and elastic preparing.

The expulsion of mercury particles from the earth is perhaps the greatest challenge today since particles can rapidly spread to enormous regions because of high portability. Different procedures and techniques have been created for the evacuation of $\mathrm{Hg}$ (II) particles from fluid solutions, for example, chemical oxidation or reduction, particles exchange, electrochemical treatment, flotation layers, desalination, chemical precipitation, film filtration, extraction, and adsorption for the expulsion of substantial metals from wastewater. The majority of these techniques have a few impediments and disadvantages when utilized for wastewater treatment. For instance, precipitation is wasteful because it creates enormous amounts of sludge that require cautious administration, and desalination and electrochemical medicines require generally high working expenses. Among various methodologies, adsorption is the most broadly utilized technique because of its effortlessness, adaptability, lack of care toward dangerous substances, and high proficiency in huge scale applications.

\section{Adsorption Experiment}

During adsorption related experiments, $20 \mathrm{~mL}$ of mercury particles were added into the solution as perchlorate salt, and along with that, about $20 \mathrm{mg}$ of the adsorbent was included and blended at $25^{\circ} \mathrm{C}$ for 
RASĀYAN J. Chem.

Vol. 13 | No. 3 |2027-2035| July - September | 2020

the period of $24 \mathrm{~h}$. At that point, the arrangement was altered and the remainder of the $\mathrm{Hg}$ (II) particles in the solution were studied by nuclear adsorption spectrophotometer. The adsorption capacity (q, in $\mathrm{mg} \cdot \mathrm{g}^{-1}$ ) was determined using the following equation ${ }^{20}$ :

$$
q=\frac{\left(C_{0}-C_{e}\right) V}{V}
$$

$\mathrm{C}_{0}$ and $\mathrm{C}_{\mathrm{e}}$ respectively denotes the initial and the equilibrium concentrations of $\mathrm{Hg}(\mathrm{II})$ ions $\left(\mathrm{mg} \cdot \mathrm{L}^{-1}\right), \mathrm{V}$ denotes the volume of the testing solution $(\mathrm{L})$, and $\mathrm{m}(\mathrm{g})$ is the quantity of the adsorbent. The effect of solution $\mathrm{pH}$ on the adsorption was studied with the $\mathrm{pH}$ ranges from $1-6$ containing $20 \mathrm{~mL}$ of mercury particles $(400 \mathrm{mg} / \mathrm{L})$.

\section{Studies on Removal of Lead}

\section{RESULTS AND DISCUSSION}

The physical, chemical properties and analytical study of wastewater used in this study were tabulated as Table-1 and Table-2.

Table-1: Physical and Chemical Properties of Wastewater employed in This Work

\begin{tabular}{c|c|c}
\hline $\mathrm{pH}$ of Wastewater & Conductivity $\left(\mu \mathrm{S} . \mathrm{cm}^{-1}\right)$ & $\mathrm{Pb}\left(\mathrm{mg}^{-\mathrm{dm}^{-3}}\right)$ \\
\hline 6.91 & 1401 & 2.07 \\
\hline
\end{tabular}

Table-2: Analytical Studies of Pb Contaminated Wastewater

\begin{tabular}{|c|c|c|c|c|c|c|c|c|c|c|c|}
\hline \multirow[b]{2}{*}{ Parameter } & \multirow[b]{2}{*}{$\begin{array}{l}\text { Initial } \\
\text { Values }\end{array}$} & \multicolumn{2}{|c|}{ Sample 1} & \multicolumn{2}{|c|}{ Sample 2} & \multicolumn{2}{|c|}{ Sample 3} & \multicolumn{2}{|c|}{ Sample 4} & \multicolumn{2}{|c|}{ Sample 5} \\
\hline & & $\begin{array}{c}\text { Dry, } \\
\text { A }\end{array}$ & $\begin{array}{c}\text { Wet, } \\
\text { A }\end{array}$ & $\begin{array}{c}\text { Dry, } \\
\text { B }\end{array}$ & $\begin{array}{c}\text { Wet, } \\
\text { B }\end{array}$ & $\begin{array}{c}\text { Dry, } \\
\text { C }\end{array}$ & $\begin{array}{c}\text { Wet, } \\
\text { C }\end{array}$ & $\begin{array}{c}\text { Dry, } \\
\text { D }\end{array}$ & $\begin{array}{c}\text { Wet, } \\
\text { D }\end{array}$ & Dry, & $\begin{array}{c}\text { Wet, } \\
\text { E }\end{array}$ \\
\hline $\mathrm{pH}$ & 6.91 & 6.826 & 7.21 & 6.93 & 7.31 & 6.93 & 7.151 & 7.11 & 6.90 & 6.96 & 6.84 \\
\hline $\begin{array}{c}\text { Conductivity } \\
\left(\mu \mathrm{S} . \mathrm{cm}^{-1}\right)\end{array}$ & 1401 & 1911 & 1402 & 1841 & 1379 & 1881 & 1391 & 1811 & 1381 & 1851 & 1411 \\
\hline $\mathrm{Pb}\left(\mathrm{mg} \cdot \mathrm{dm}^{-3}\right)$ & 2.067 & 1.35 & 1.56 & 1.35 & 1.66 & 1.456 & 1.76 & 1.46 & 1.87 & 1.56 & 1.87 \\
\hline
\end{tabular}

The different effective methodologies such as chemical precipitation, ion exchange, membrane separation, flocculation, electrolysis, and adsorption were carried out for treating heavy metal ions contaminated wastewaters. Among these various methods, the adsorption technique using Nanocomposite is declared as promising methodology due to its secure, cheap, uncomplicated, and more productivity merits. Recently, Panchal et $\mathrm{al}^{21}$ employed peanut hull to decolorize Yamuna water and similarly, Rai et $\mathrm{al}^{22}$ used Almond shell activated carbon to remove Methylene blue from aqueous solutions. Baalamurugan et $\mathrm{a}^{23}$ employed steel slag composite on the treatment of methylene blue dye.

Figure-5 shows the graph of adsorption analysis carried out on $\mathrm{Pb}(\mathrm{II})$ when GO-Si Nanocomposite is subjected to exposure.
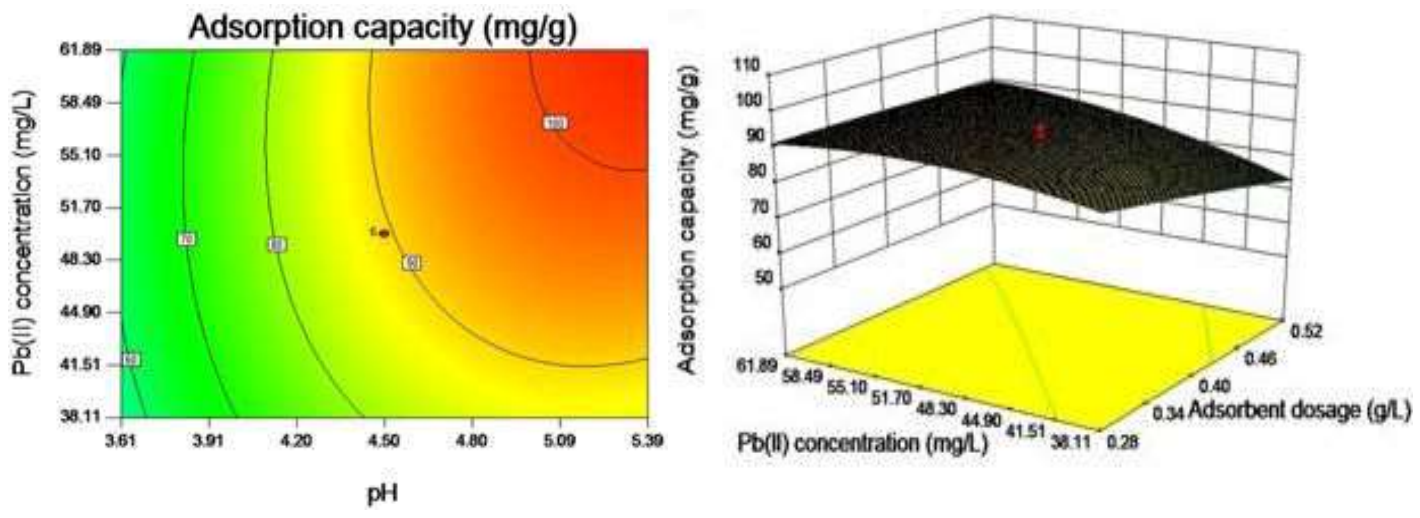

Fig.-5: Adsorption Capacity Analysis of Lead from Waste Water 
RASĀYAN J. Chem.

Vol. 13 | No. 3 |2027-2035| July - September | 2020

\section{Effects of initial solution pH}

To demonstrate the effect of initial solution $\mathrm{pH}$ on adsorption performance, adsorption experiments were carried out under different $\mathrm{pH}$ values ranging from 3 to 13, is depicted in Fig.-6. When $\mathrm{pH}$ is less than 5, $\mathrm{Pb}^{2+}$ is the dominant species of $\mathrm{Pb}$ (II) which is represented in Fig.-7.

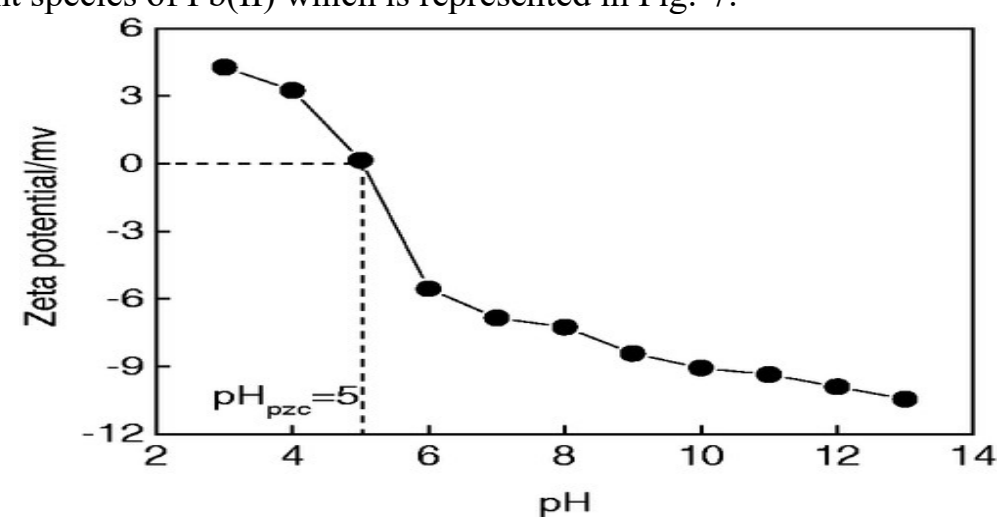

Fig.-6: Zeta Potential of GO-Si Variation with Solution $\mathrm{pH}$

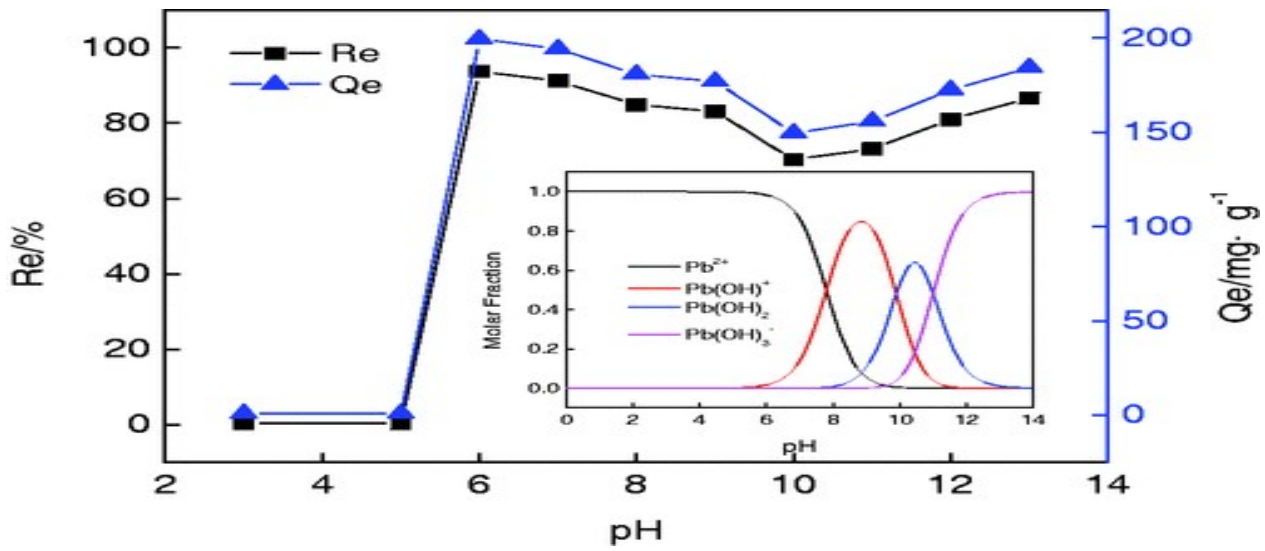

Fig.-7: Effect of Initial pH on $\mathrm{Pb}(\mathrm{II})$ Adsorption

\section{Adsorption Mechanism}

In this work, different adsorption models were used to study the adsorption system, its thermodynamics, and better understanding. The obtained data with $\mathrm{Pb}$ (II) adsorption was fitted with adsorption isotherm models and found that Temkin model was best fitted than Langmuir, Freundlich, and D-R. The data was poorly fitted with Freundlich and D-R.

Temkin isotherm model expects that the adsorption warmth of a considerable number of atoms in the layer directly diminishes with the inclusion due to concoction connections between adsorbent and adsorbate molecules. Here, the adsorption can easily be described by uniform conveyance of the coupling energies, up to a most extreme restricting vitality. Because of the presumptions of the Temkin model, we can conclude that, the monolayer chemisorption is the primary adsorption component in our work. This may be attributed to a lot of equitably conveyed oxygen-containing bunches, as the dynamic destinations for adsorption. In this work, $\Delta \mathrm{H}$ was found to be $-91.39 \mathrm{~kJ} / \mathrm{mol}, \Delta \mathrm{G}$ was determined as $-9.55 \mathrm{~kJ} / \mathrm{mol}$ and $\Delta \mathrm{S}$ was estimated as $-279.31 \mathrm{~J} /(\mathrm{K} . \mathrm{mol})$ at the temperature of $293 \mathrm{~K}$.

This study clearly illustrates that the adsorption is exothermic, entropy diminishing, and unconstrained procedure. The absolute value of $\Delta \mathrm{H}$ is higher than $20 \mathrm{~kJ} \mathrm{~mol}^{-1}$, suggesting a solid chemical interaction among adsorbent and adsorbates, a proof of chemisorption, which supports the end drawn from the Temkin model. The absolute value of $\Delta \mathrm{G}$ diminished with the ascent of temperature, demonstrating more fragile adsorption under higher temperature, as appeared by the inset. During the adsorption procedure, the $\mathrm{Pb}(\mathrm{II})$ be adsorbed by GO-Si adsorbent from the solution, prompting entropy decline. $\Delta \mathrm{S}<0$ demonstrates that the level of opportunity diminishes during the adsorption procedure. Based on the $\mathrm{R}^{2}$ values (straight connection coefficient) obtained during different experiments, the adsorption dynamic 
RASĀYAN J. Chem.

Vol. 13 | No. 3 |2027-2035| July - September | 2020

models best fitted with $\mathrm{Pb}(\mathrm{II})$ adsorption was found to be liquid film diffusion followed by pseudosecond-order and then followed by an intra-particle diffusion model. The data does not fit with the pseudo-first-order model.

The pseudo-first-order model agrees with the most reduced linear correlation coefficient among all the four kinetic models, with the fit aftereffect of harmony adsorption amount being $62.28 \mathrm{mg} / \mathrm{g}$, which is far lower than the test consequence of $190.17 \mathrm{mg} / \mathrm{g}$, demonstrating that pseudo-first-request model isn't proper to depict the adsorption procedure. Conversely, pseudo-second-order model gives $\mathrm{R}^{2}$ value of 0.99 and a fit consequence of equilibrium adsorption amount $190.8 \mathrm{mg} / \mathrm{g}$, which is near that of the exploratory outcome, implying that pseudo-second-order model is fitting for depicting the adsorption energy, with chemisorption the rate-controlling advance, which is predictable with the ends drawn from Temkin model and the estimation of $\Delta \mathrm{H}$.

The directly dependent coefficient of the intra-molecule dispersion model and fluid movie dissemination model is 0.98 and 0.99 , individually. In any case, the all-encompassing fit line of the last experience the first point, while the previous not, inferring that the adsorption procedure is constrained by both chemisorption and fluid film dissemination, though intra-molecule dispersion is certifiably not a noteworthy rate-controlling advance. This might be credited to the simplicity of the $\mathrm{Pb}(\mathrm{II})$ dissemination inside GO-Si, which is facilitated by the slender graphene sheets in its structure. An obvious impact of temperature on the adsorption additionally bolsters the chemisorption nature.

\section{Studies on the Removal of Mercury}

The present work expects to express the performance of GO-Si adsorbent on $\mathrm{Hg}$ (II) by removing it from wastewater. Mercury is toxic and it is a neurotoxin that can affect the central sensory system.

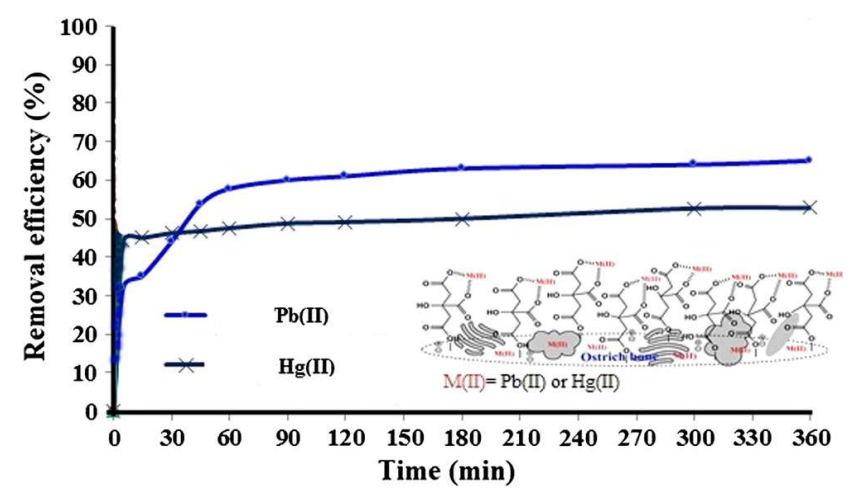

Fig.-8: Removal Efficiency of Lead and Mercury by GO-Si Composite

So, it is very essential to remove the presence of mercury from wastewater. In the above graphical representation Fig.-8, the expulsion proficiency of mercury and lead using GO-Si composite is given based on time.

\section{Adsorption Kinetics}

The adsorption of $\mathrm{Hg}(\mathrm{II})$ by the adsorbents depends upon the amount of $\mathrm{pH}$ value. Thus, $\mathrm{pH}$ can influence the capacity of adsorption of $\mathrm{Hg}$ (II) particles by the GO-Si Nanocomposite adsorbent. The impact of solution $\mathrm{pH}$ on $\mathrm{Hg}$ (II) adsorption was examined in the scope of 1.0-6.0 at $298 \mathrm{~K}$. With the increase in $\mathrm{pH}$ value, the $\mathrm{Hg}(\mathrm{II})$ adsorption capacity of both adsorbents was increased until $\mathrm{pH} 4.0$, and then it began to decrease. At $\mathrm{pH} \mathrm{4}$, the adsorption limit of GO-Si was $266 \mathrm{mg} / \mathrm{g}$, which surpassed a large portion of the adsorbents announced, and for GO, it was $202 \mathrm{mg} / \mathrm{g}$.

The impact of $\mathrm{pH}$ on adsorption limit. To quantify the adsorption energy, the adsorbents $(20 \mathrm{mg})$ were added to $20 \mathrm{~mL}$ of solution with a mercury particle concentration of $400 \mathrm{mg} / \mathrm{L}$ and blended at $25^{\circ} \mathrm{C}$. Mixing began at zero time of the adsorption process. At that point, the samples were taken simultaneously interim, and the adsorption capacity was inspected. The kinetic adsorption plots were made according to pseudo-first-order and pseudo-second-order kinetic models. The pseudo-first-order kinetic model was:

The pseudo-second-order kinetic model was:

$$
\ln \left(q_{e}-q_{t}\right)=\ln q_{e}-k_{1} t
$$


RASĀYAN J. Chem.

Vol. 13 | No. 3 |2027-2035| July - September | 2020

$$
\frac{\mathrm{t}}{\mathrm{q}_{\mathrm{t}}}=\frac{1}{\mathrm{k}_{2} \mathrm{q}_{\mathrm{e}}^{2}}+\frac{\mathrm{t}}{\mathrm{q}_{\mathrm{e}}}
$$

Here, $\mathrm{q}_{\mathrm{e}}$ denotes adsorption capacity at equilibrium $(\mathrm{mg} / \mathrm{g}), \mathrm{q}_{\mathrm{t}}$ denotes adsorption capacity at any time, $\mathrm{t}$ $(\mathrm{mg} / \mathrm{g})$, and $\mathrm{k}_{1}(1 / \mathrm{min})$ and $\mathrm{k}_{2}(\mathrm{~g} /(\mathrm{mg} \cdot \mathrm{min}))$, are the rate constants of first-order and second-order adsorption, respectively.

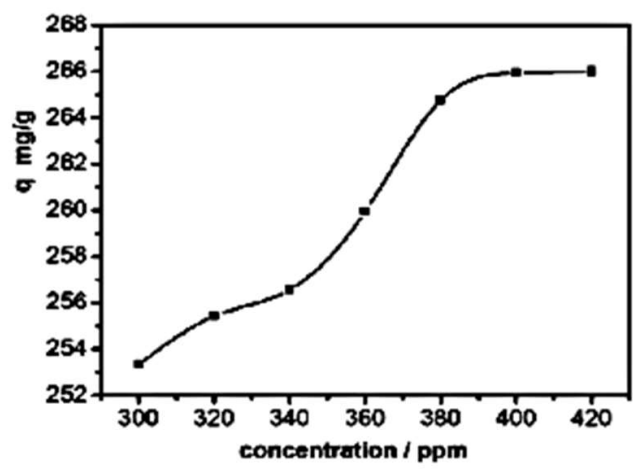

Fig.-9a: $\mathrm{Hg}^{2+}$ Concentration on Adsorption Quantity

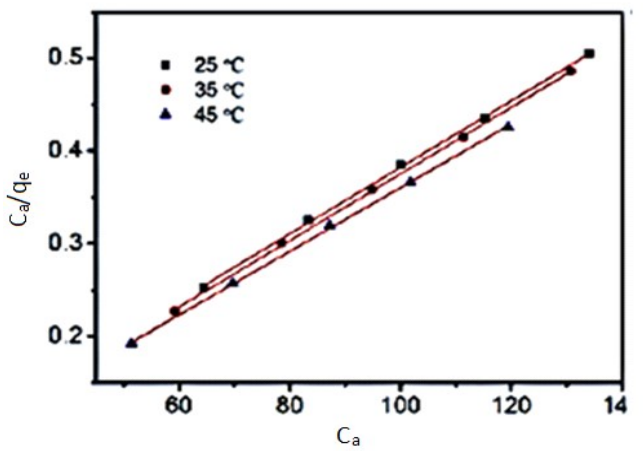

Fig.-10a: Langmuir Isotherm For the Adsorption of $\mathrm{Hg} 2+$ at Different Temperatures

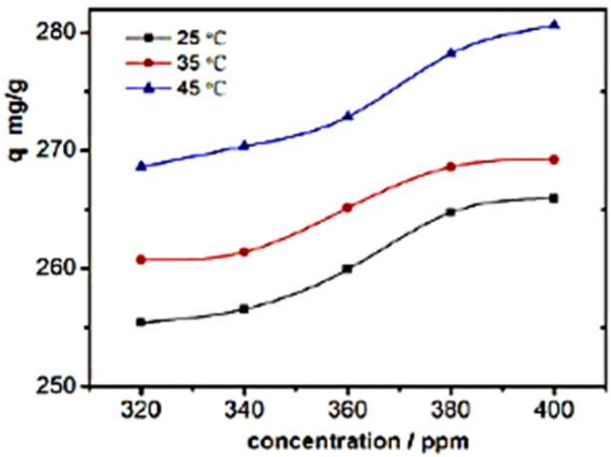

Fig.-9b: Adsorption Quantity of $\mathrm{Hg}^{2+}$ at Different Temperatures

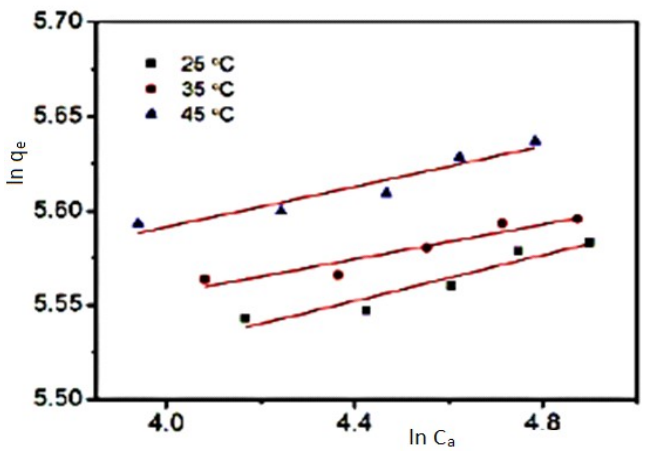

Fig.-10b: Freundlich Isotherm For the Adsorption of $\mathrm{Hg} 2+$ at Different Temperatures

The influence of the initial concentration of $\mathrm{Hg}$ (II) ion on adsorption at the temperature of $298 \mathrm{~K}$ was investigated, and the obtained results were clearly illustrated in Fig.-9a. It can easily be observed that the adsorption amount of $\mathrm{Hg}(\mathrm{II})$ was enhanced with the initial $\mathrm{Hg}$ (II) concentrations and then gradually reached a platform, which was due to the saturation adsorption on the active sites of the GO-Si. Fig.-9b showed the adsorption isotherms of GO-Si at different temperatures, such as $25^{\circ} \mathrm{C}, 35^{\circ} \mathrm{C}$, and $45^{\circ} \mathrm{C}$. It was observed that as the temperature increased, the adsorption amount of $\mathrm{Hg}^{2+}$ also increased. The isotherm data were fitted according to the Langmuir and Freundlich equations.

The obtained results clearly illustrate that, the Langmuir equation was well fitted the adsorption isotherm due to a higher correlation value than that of the Freundlich equation were shown in Fig.-10a and Fig.$10 \mathrm{~b}$. In addition to that, the adsorption capacity of $\mathrm{q}_{\mathrm{m}}$ acquired by the Langmuir theory was $278 \mathrm{mg} / \mathrm{g}$, which is very close to the obtained experimental value. This obtained results suggested monolayer adsorption of $\mathrm{Hg}(\mathrm{II})$ by GO-Si adsorbent.

\section{CONCLUSION}

In this study, the analysis shows that GO-Si was found to be the most effective nanoparticle suitable for mercury and lead removal. The impact of different adsorption parameters including initial $\mathrm{pH}$, adsorbent dose, temperature, efficiency, and contact time were analyzed. The results clearly illustrated that, with GO-Si, all data were well fitted with both the pseudo-second-order kinetic and Langmuir models. The thermodynamic computations demonstrated that the expulsion of lead and mercury on GO-Si was found to be an unconstrained and exothermic procedure. The greatest adsorption measure of lead and mercury 
RASĀYAN J. Chem.

Vol. 13 | No. 3 |2027-2035| July - September | 2020

on GO-Si achieved were $347.2 \mathrm{mg} / \mathrm{g}$ and $266 \mathrm{mg} / \mathrm{g}$. Additionally, GO-Si Nanocomposite could be adequately regenerated by straightforward warming treatment and reused at least five times keeps running without critical loss of adsorption limit. In the future, GO-Si can be highly recommended and utilized in water treatment for its high adsorptive capacity due to the combined effect of GO and silica nanoparticles at less cost.

\section{REFERENCES}

1. Y. Al-Degs, M.A.M. Khraisheh, S.J. Allen, M.N. Ahmad, Water Research, 34(3), 927(2000), DOI: 10.1016/S0043-1354(99)00200-6

2. Y. Yu, Y. Zhuang, Z. H. Wang, M. Q. Qiu, Chemosphere, 54(3), 425(2004), DOI:10.1016/S00456535(03)00654-4

3. S. William, J.R. Hummers, and R.E.Offeman, Journal of American Chemical Society, 80(6), 1339(1958), DOI:10.1021/ja01539a017

4. S. Tabesh, F. Davar, M.R. Loghman-Estarki, Journal of Alloys Compounds, 730, 441(2018), DOI:10.1016/j.jallcom.2017.09.246

5. M.S. Sajab, C.H. Chia, S. Zakaria, P.S. Khiew, Bioresource Technology, 128, 571(2013), DOI: 10.1016/j.biortech.2012.11.010

6. G.R. Patzke, F. Krumeich, R. Nesper, Angewandte Chemie International Edition, 41(14), 2446(2002), DOI:10.1002/1521-3773(20020715)41:14<2446::AID-ANIE2446>3.0.CO;2-K

7. D. Rickerby, M. Morrison, Journal of Science and Technology of Advanced Materials, 8(1-2), 19(2007), DOI:10.1016/j.stam.2006.10.002

8. I. Tyagi, V. Gupta, H. Sadegh, R.S. Ghoshekandi, A.S.H. Makhlouf, Science, Technology and Development, 34(3), 195(2017), DOI:10.3923/std.2015.195.214

9. R.J. Bhargavi, U. Maheshwari, S. Gupta, International Journal of Industrial Chemistry, 6(1), 31(2015), DOI:10.1007/s40090-014-0029-1

10. G.K. Ramesha, A. Vijaya Kumara, H.B. Muralidhara, S. Sampath, Journal of Colloid and Interface Science, 361(1), 270(2011), DOI:10.1016/j.jcis.2011.05.050

11. J. Balapanuru, J.X. Yang, S. Xiao, Q. Bao, M. Jahan, L. Polavarapu, J. Wei, Q.H. Xu, K.P. Loh, Angewandte Chemie International Edition, 49(37), 6549(2010), DOI:10.1002/anie.201001004

12. L.C. Oliveira, R.V. Rios, J.D. Fabris, V. Garg, K. Sapag, R.M. Lago, Carbon, 40(12), 2177(2002), DOI: 10.1016/S0008-6223(02)00076-3

13. C. Wang, C. Feng, Y. Gao, X. Ma, Q. Wu, Z. Wang, Chemical Engineering Journal, 173(1), 92(2011), DOI:10.1016/j.cej.2011.07.041

14. S. Bai, X. Shen, X. Zhong, Y. Liu, G. Zhu, X. Xu, K. Chen, Carbon, 50(6), 2337(2012), DOI:10.1016/j.carbon.2012.01.057

15. D.H.K. Reddy, S.M. Lee, Advances in Colloid and Interface Science, 201(202), 68(2013), DOI: $10.1016 /$ j.cis.2013.10.002

16. D.K. Padhi, T.K. Panigrahi, K. Parida, S.K. Singh, P.M. Mishra, ACS Sustainable Chemical Engineering, 5(11), 10551(2017), DOI:10.1021/acssuschemeng.7b02548

17. M. Franzreb, M. Siemann-Herzberg, T.J. Hobley, O.R. Thomas, Applied microbiology and biotechnology, 70(5), 505 (2006), DOI:10.1007/s00253-006-0344-3

18. J. Xu, L. Wang, and Y. Zhu, Langmuir, 28(22), 8418 (2012), DOI:10.1021/la301476p

19. R. Karthik, S. Meenakshi, Chemical Engineering Journal 263, 168(2015), DOI:10.1016/j.cej.2014.11.015

20. V. Panchal, A. Ghosh, P.C. Tomar, and S.S. Chapadgaonkar, Rasayan Journal Chemistry, 13(2), 949(2020), DOI: 10.31788/RJC.2020.1325404

21. M.K. Rai, B.S. Giri, R.S. Singh, and B.N. Rai, Rasayan Journal of Chemistry, 13(2), 979(2020), DOI: 10.31788/RJC.2020.1325627

22. J. Baalamurugan, V.G. Kumar, B.S.N. Prasad, K. Govindaraju, Rasayan Journal of Chemistry, 13(2), 1014(2020), DOI: 10.31788/RJC.2020.1325715

[RJC-5827/2020] 